\title{
Roles of BTLA in Immunity and Immune Disorders
}

\author{
Zhaochen Ning ${ }^{1,2}$, Keyan $\mathrm{Liu}^{3}$ and Huabao Xiong ${ }^{1,2 *}$ \\ 1 Institute of Immunology and Molecular Medicine, Jining Medical University, Jining, China, ${ }^{2}$ Jining Key Laboratory of \\ Immunology, Jining Medical University, Jining, China, ${ }^{3}$ Department of Public Health, Jining Medical University, Jining, China
}

\section{OPEN ACCESS}

Edited by:

llan Bank,

Sheba Medical Center, Israel

Reviewed by: Jose-Ignacio Rodriguez-Barbosa, Universidad de León, Spain John R. Sedy, Sanford Burnham Prebys Medical Discovery Institute, United States

*Correspondence:

Huabao Xiong xionghb/@yahoo.com

Specialty section:

This article was submitted to T Cell Biology, a section of the journal Frontiers in Immunology

Received: 26 January 2021 Accepted: 12 March 2021

Published: 29 March 2021

Citation:

Ning Z, Liu K and Xiong H (2021) Roles of BTLA in Immunity and Immune Disorders.

Front. Immunol. 12:654960. doi: 10.3389/fimmu.2021.654960
$B$ and T lymphocyte attenuator (BTLA) is one of the most important cosignaling molecules. It belongs to the CD28 superfamily and is similar to programmed cell death-1 (PD-1) and cytotoxic T lymphocyte associated antigen-4 (CTLA-4) in terms of its structure and function. BTLA can be detected in most lymphocytes and induces immunosuppression by inhibiting $B$ and $T$ cell activation and proliferation. The BTLA ligand, herpesvirus entry mediator (HVEM), does not belong to the classic B7 family. Instead, it is a member of the tumor necrosis factor receptor (TNFR) superfamily. The association of BTLA with HVEM directly bridges the CD28 and TNFR families and mediates broad and powerful immune effects. Recently, a large number of studies have found that BTLA participates in numerous physiopathological processes, such as tumor, inflammatory diseases, autoimmune diseases, infectious diseases, and transplantation rejection. Therefore, the present work aimed to review the existing knowledge about BTLA in immunity and summarize the diverse functions of BTLA in various immune disorders.

Keywords: BTLA, coinhibition, inflammation, cancer immunotherapy, HVEM

\section{INTRODUCTION}

$\mathrm{B}$ and T lymphocyte attenuator (BTLA) is a member of the CD28 superfamily. Its gene is localized in the q13.2 region of chromosome 3 and consists of 5 exons with a total length of $870 \mathrm{bp}$. The protein structure of BTLA is similar to programmed cell death-1 (PD-1) and cytotoxic T lymphocyte associated antigen-4 (CTLA-4), which includes extracellular domain, transmembrane domain and cytoplasmic domain $(1,2)$. The cytoplasmic domain contains growth factor receptorbound protein-2 (Grb-2) association motif, immunoreceptor tyrosine-based switch motif (ITSM), and immunoreceptor tyrosine-based inhibitory motif (ITIM). HVEM binding activates tyrosine phosphorylation of the ITIM in BTLA and leads to the recruitment of the Src homology domain 2 (SH2)-containing protein tyrosine phosphatases, SHP-1 and SHP-2, which generally mediate immunosuppressive effects $(3,4)$. Interestingly, binding of the Grb-2 association motif with Grb2 leads to the recruitment of PI3K protein subunit p85 and T cell activation (5). At present, herpes virus entry mediator (HVEM), which belongs to the tumor necrosis factor receptor superfamily, is the only identified ligand that can be detected in human cells (1). HVEM can interact with BTLA in a cis or trans manner. On cells coexpressing BTLA and HVEM, BTLA can interact with HVEM in cis, whereas trans interaction occurs when BTLA and HVEM are expressed on different cells $(2,6)$. In addition to BTLA, HVEM can also interact with CD160, lymphotoxin- $\alpha$, LIGHT (TNFSF14), 
and synaptic adhesion-like molecule 5 (SALM5) (7-9). Notably, BTLA and CD160 compete for the same binding site within the CRD1/CRD2 region of HVEM, while LIGHT independently binds the opposite side of HVEM within the CRD2/CRD3 region $(1,8,10)$. BTLA can be extensively expressed in lymph nodes, thymus, and spleen, but little or no expression is detected in organs, such as the heart, kidney, brain, and liver (11). Among immune cells, BTLA is mainly expressed in B and T cells. In mouse spleen, the expression of BTLA is higher in B cells than T cells. With regard to T cells, BTLA expression can be detected on both $\mathrm{CD} 4^{+}$and $\mathrm{CD} 8^{+} \mathrm{T}$ cells, whereas $\mathrm{CD} 4^{+} \mathrm{T}$ cells express more BTLA than $\mathrm{CD}^{+} \mathrm{T}$ cells (12). Besides, its expression can also be detected in innate immune cells, such as dendritic cells (DCs) and monocytes (13). HVEM binding to BTLA exerts direct negative effects on the proliferation and activation of $\mathrm{B}$ and $\mathrm{T}$ cells (14). As a result, they affect a variety of physiopathological processes. This review aimed to summarize the recent results on the effects of BTLA in regulating immune cell function and to explore its potential role in immune disorders.

\section{BTLA EFFECTS IN IMMUNOCYTES}

\section{BTLA and T Cells}

BTLA levels vary during $\mathrm{T}$ cell differentiation and activation processes. Specifically, BTLA is expressed in naive T cells, and the expression transiently increases upon activation, but is decreased in activated $\mathrm{T}$ cells (15-18). Moreover, the interaction manners between BTLA and HVEM also changes. Under homeostatic conditions, HVEM and BTLA interact in cis to provide intrinsic inhibitory signals. Upon $\mathrm{T}$ cell activation, HVEM is internalized, which allows BTLA to interact with HVEM in trans $(6,10)$. BTLA-deficient mice exhibit no defects in lymphocyte development, suggesting that BTLA is not necessary for $\mathrm{T}$ cell development (19). However, BTLA can significantly inhibit $\mathrm{T}$ cell activation and proliferation. BTLAdeficient $\mathrm{T}$ cells show increased proliferation (4) and are hyperresponsive to TCR-mediated activation (19). BTLA agonistic monoclonal antibody $(\mathrm{mAb})$ suppresses the proliferation of $\mathrm{T}$ cells and the secretion of interleukin (IL)-10 and interferon $\gamma$ (IFN- $\gamma$ ) upon anti-CD3 stimulation (20). Antibodies targeting BTLA enhance the proliferation of $\mathrm{CD}^{+}$ T cells and blocking BTLA in combination with PD-1 is found to be effective in enhancing the exhausted human $\mathrm{T}$ cell response (21). Krieg et al. found that $\mathrm{BTLA}^{-/-}$mice showed an elevated memory $\mathrm{CD}^{+} \mathrm{T}$ cell count and proposed that the increased $\mathrm{T}$ cell proliferation mediated by BTLA deficiency was associated with alterations in $\mathrm{T}$ cell memory subsets but not co-inhibition (22). However, Deppong et al. discovered that T cells with BTLA deficiency exhibited no enhanced proliferation, but showed decreased death (23). In addition, BTLA contributes to the induction of peripheral tolerance in $\mathrm{CD}^{+}$and $\mathrm{CD}^{+} \mathrm{T}$ cells (24). In naive T-cells, BTLA and HVEM form a cisheterodimeric complex, which blocks other co-signaling molecules from binding to HVEM and stimulating the NF- $\mathrm{KB}$ signaling pathway, thus maintaining the tolerance of $\mathrm{T}$ cells (6).
BTLA engagement has been suggested to facilitate SHP-1 and SHP-2 recruitment $(3,4)$. However, Chemnitz et al. reported that SHP-1 recruitment was not related to the function of BTLA, as blocking SHP-1 recruitment did not affect the function of BTLA (25). Paradoxically, it was recently shown that BTLA preferentially recruits SHP-1 to suppress $\mathrm{T}$ cell signaling more efficiently $(26,27) . \gamma \delta \mathrm{T}$ cells can quickly produce inflammatory cytokines at sites of barrier to protect against pathogens. BTLA can limit $\gamma \delta \mathrm{T}$ cell numbers and control proliferation and cytokine secretion in mature lymph node $\gamma \delta \mathrm{T}$ cells (28). $\mathrm{V} \gamma 9 \mathrm{~V} \delta 2$ cells are the main subset of $\gamma \delta \mathrm{T}$ cells in peripheral blood that are reactive to tumors and microbial agents, and BTLA was found to be strongly expressed in resting $\mathrm{V} \gamma 9 \mathrm{~V} \delta 2 \mathrm{~T}$ cells. BTLA engagement inhibited $\mathrm{V} \gamma 9 \mathrm{~V} \delta 2 \mathrm{~T}$ cell proliferation, while targeting BTLA resulted in the enhancement of $\mathrm{V} \gamma 9 \mathrm{~V} \delta 2$ TCR-mediated signaling (29).

\section{BTLA and B Cells}

BTLA in B cells has rarely been studied compared to that in T cells. In human B cell subsets, mature peripheral B cells display the most significant BTLA level, whereas a uniform BTLA expression is observed in naive, transitional, and memory peripheral B cells, and the lowest level is detected in bone marrow-derived precursor B cells (30). In addition, BTLA levels are downregulated in B cells of the aged, which is related to the decreased reactivity to the trivalent influenza vaccine (31). In mouse spleen, compared to T cells, B cells display higher surface BTLA level $(12,32)$. Consistent with its effect on the development of T cells, BTLA does not significantly affect the development of B cells, because normal growth of lymphocytes is detected in mice with BTLA deficiency $(4,19)$. Moreover, it was found that BTLA/ HVEM ligation can suppress the functions of B cells (such as proliferation, cytokine secretion, and co-stimulatory molecule upregulation) (30, 33). Engagement of BTLA recruits SHP-1, leading to reduced activation of BCR downstream signaling molecules (30). However, Zhang et al. reported that BTLA antibodies had no effect on lipopolysaccharide (LPS)- or antiIgM antibody-induced B cell proliferation in vitro (34). Regarding helper $\mathrm{T}$ (Th) cells, follicular Th (Tfh) cells represent the dominant subset that promotes antibody secretion by $\mathrm{B}$ cells. Mintz et al. discovered that HVEM engagement of BTLA on Tfh cells reduced $\mathrm{T}$ cell receptor (TCR) signaling and CD40 ligand mobilization to the synapse, thereby reducing the help to $\mathrm{B}$ cells and inhibiting B cell proliferation (35). Additionally, it was found that BTLA could inhibit IL-21 production by Tfh cells to suppress the development of germinal center B cells and subsequent IgG responses (36).

\section{BTLA and DCs}

As its name implies, BTLA shows preferential expression in $\mathrm{T}$ and $\mathrm{B}$ cells, yet its expression can also be detected in additional immune cells, such as DCs. Immature DCs express lower levels of BTLA, and BTLA expression increases with maturation (37). The number of DCs in $\mathrm{BTLA}^{-/-}$mice spleen was found to be similar to that in wild-type mice, suggesting that BTLA is not essential for DC development (38). The HVEM-BTLA pathway 
plays an important role in regulating DC homeostasis. The lymphotoxin $\beta$ receptor signaling pathway triggers the proliferation of DCs, while the HVEM-BTLA signaling pathway suppresses DC proliferation, suggesting that the HVEM-BTLA pathway provides an inhibitory checkpoint for DC homeostasis (39). Xin et al. reported that BTLA overexpression suppressed DC maturation and enhanced the immune tolerance of immature DCs (40). BTLA can inhibit tolllike receptor 4 signaling and proinflammatory cytokine production in DCs, thereby inhibiting LPS-induced endotoxic

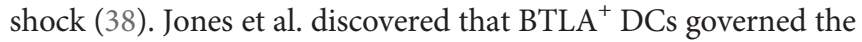
conversion of peripheral Treg cells by upregulating CD5, thus enhancing the tolerance of peripheral Treg cells (41). Moreover, active pulmonary tuberculosis drives BTLA expression in DCs, thereby inhibiting Th17 and Th22 responses induced by DCs and promoting Treg and Th2 differentiation (42). Further, urothelial cancer induces the overexpression of BTLA in DCs, resulting in reduced secretion of effector cytokines (43).

\section{THE FUNCTIONS OF BTLA IN IMMUNE-RELATED DISEASES}

\section{BTLA and Tumors}

BTLA is found to be expressed in tumor-infiltrating lymphocytes (TILs) and is often associated with impaired anti-tumor immune response. Upregulated BTLA expression in gallbladder cancer (GBC) plays a role in inhibiting anticancer immunity, and an increased proportion of $\mathrm{BTLA}^{+} \mathrm{CD}^{+}$cells is related to the unfavorable outcome of GBC patients (44). In hepatocellular carcinoma (HCC) cases, the expression level of BTLA markedly increases in circulating $\mathrm{CD}^{+}$cells rather than in $\mathrm{CD}^{+} \mathrm{T}$ cells $(45,46)$. Besides, blocking the BTLA/HVEM signaling pathway can promote IFN- $\gamma$ secretion by circulating $\mathrm{CD} 4^{+}$and $\mathrm{CD} 8^{+} \mathrm{T}$ cells (45). BTLA ${ }^{+} \mathrm{T}$ cells show increased levels of additional checkpoint molecules, such as PD-1, lymphocyte-activation gene-3, T cell immunoglobulin and mucin-do-main-containing molecule-3 (TIM-3). In addition, these cells exhibit a poorly differentiated phenotype, reduced cytolysis, and increased proliferation potential among patients with diffuse large B-cell lymphoma (DLBCL). Further, increased BTLA levels are related to an advanced disease stage in DLBCL patients (47). BTLA expression is elevated in $\mathrm{T}$ cells from patients with melanoma (48, 49). Furthermore, PD- $1^{+} \mathrm{TIM}-3^{-} \mathrm{CD} 8^{+} \mathrm{T}$ cells expressing BTLA are the largest tumor-specific $\mathrm{CD}^{+} \mathrm{T}$ cell subset among melanoma cases that show partial dysfunction with decreased IFN- $\gamma$ production compared with BTLA ${ }^{-} \mathrm{T}$ cells (49). BTLA is highly expressed in type I NKT cells in murine autochthonous mammary tumors, and BTLA-neutralizing antibodies can inhibit tumor proliferation and pulmonary metastasis (50). BTLA expression was also found to be upregulated in $\mathrm{T}$ cells from patients with lung cancer (51). In addition, soluble BTLA (sBTLA) in plasma is significantly associated with the risk of death in patients with clear cell renal cell cancer, suggesting that sBTLA has a similar role to membranous BTLA in inhibiting $\mathrm{T}$ cell response (52). However, some studies have reported contradictory results. For instance, as suggested by Song et al., BTLA levels decreased in colorectal cancer tissues in comparison with levels in matched non-carcinoma tissues. In addition, decreased BTLA levels predicted poor overall survival and less LNM (53). Notably, BTLA is suggested to trigger both inhibitory and survival signaling, and may have a context-specific function in TILs (7). Although BTLA is a co-inhibitory receptor, higher frequencies and numbers of BTLA-expressing $\mathrm{CD}^{+}$TILs are markedly associated with positive adoptive cell therapy responses among melanoma cases (54). This team further found that BTLA marks a less-differentiated TIL subset, which displays enhanced resistance to apoptosis and improved survival after tumor killing $(55,56)$. Besides, growing evidence suggests that polymorphisms of BTLA increase susceptibility to a wide range of cancers. Rs1982809 is a functional single nucleotide polymorphism (SNP) that affects BTLA $3^{\prime}$-UTR activity and BTLA expression, and has been found to be associated with a higher incidence of renal cell carcinoma (57), chronic lymphocytic leukemia (58) and esophagogastric junction adenocarcinoma (59). Five BTLA gene SNPs were found to be related to progesterone receptor, estrogen receptor, tumor size, p53, and C-erbB-2 statuses among Chinese females from the northeast Heilongjiang Province (60). However, Cao et al. found no significant relationship between BTLA polymorphisms and esophageal squamous cell carcinoma (61).

\section{BTLA in Sepsis and Inflammatory Diseases}

BTLA negatively regulates $\mathrm{T}$ cell-mediated inflammation. $\mathrm{BTLA}^{-/-}$mice experience a prolonged duration of allergic airway inflammation and enhanced recruitment of inflammatory cells relative to those in wild-type mice (62). Moreover, DNFB-mediated contact hypersensitivity, $\mathrm{CD}^{+} \mathrm{T}$ cell proliferation, and IFN- $\gamma$ generation increased in $\mathrm{BTLA}^{-/-}$ mice, whereas these effects were reversed by an agonistic antiBTLA antibody (63). The BTLA ${ }^{+}$T cell frequency is elevated in the mucosa and blood of mice with colitis, and BTLA can control inflammatory responses by upregulating Foxp3 expression (64). In a Con A challenge model of acute hepatitis, $\mathrm{BTLA}^{-/-}$mice showed reduced survival and increased early secretion of serum cytokines, which was partly due to the negative regulation of NKT cells by BTLA (65). Moreover, Shi et al. discovered that BTLA could induce the self-tolerance of $\mathrm{CD}^{+} \mathrm{BTLA}^{+} \mathrm{T}$ cells to reduce the attack on hepatocytes, thus regulating hepatic homeostasis in a Con A-induced hepatitis model in zebrafish (66).

Notably, a growing body of research suggests that BTLA plays an important role in sepsis. Sepsis mortality is prevented in mice with BTLA deficiency, which presents with reduced leukocyte recruitment into the peritoneum, reduced IL-10 secretion, increased bacterial clearance, and suppressed neutrophil activation (67). Besides, it is further found that critically ill sepsis patients show a markedly increased proportion of $\mathrm{BTLA}^{+} \mathrm{CD}^{+}$lymphocytes in peripheral blood, which is associated with a subsequent infection (68). The BTLA level in Tregs (69) and plasma concentration of sBTLA $(70,71)$ are elevated in sepsis cases, and they are related to sepsis severity. 
However, some studies have reported different results. Specifically, relative to that in normal subjects, the number of $\mathrm{BTLA}^{+} \mathrm{CD} 4^{+} \mathrm{T}$ cells decreased among patients with severe sepsis, and a lower percentage of $\mathrm{BTLA}^{+} \mathrm{CD} 4^{+} \mathrm{T}$ cells during the early stage of sepsis was associated with the severity and mortality of sepsis patients (72). Furthermore, Spec et al. reported that differences in BTLA levels in $\mathrm{CD}^{+}$and $\mathrm{CD}^{+} \mathrm{T}$ cells were not statistically significant between patients with Candida sepsis and controls (73). Interestingly, different clones of BTLA antibodies have two contradictory effects, including neutralizing and potentiating effects on BTLA-mediated signaling $(74,75)$. Cheng et al. reported that BTLA antibody treatment increased the levels of cytokines and chemokines and promoted the recruitment of inflammatory cells into the peritoneal cavity, leading to deteriorated organ damage and increased mortality in mice with hemorrhagic shock/sepsis (76). However, Kobayashi et al. found that a BTLA antibody rescued mice from LPS-induced endotoxic shock (38). The authors also suggested that mice with BTLA deficiency showed high susceptibility to LPS-induced endotoxic shock and that LPSmediated production of IL-12 and tumor necrosis factor $\alpha$ significantly increased in macrophages and DCs of mice with BTLA deficiency (38). These discrepant results from different studies may be related to the different functions of the antibodies used. Moreover, genetic variations in BTLA are associated with sepsis morbidity. In addition to increasing cancer susceptibility, Rs1982809 is also associated with the incidence of sepsis and multiple organ dysfunction scores (77).

\section{BTLA and Autoimmune Diseases}

BTLA is suggested to play a vital role in the protection from autoimmunity. Mice with BTLA deficiency exhibit increased antigen-specific IgG responses and are sensitive to experimental autoimmune encephalomyelitis (EAE) (4, 78). BTLA deficiency results in spontaneous development of autoimmune hepatitis-like disease, which is characterized by elevated transaminase levels, interface hepatitis, and hepatic spotty necrosis (79). The number of BTLA-expressing B cells and $\mathrm{CD} 9^{+} / \mathrm{BTLA}^{+} / \mathrm{IL}-10^{+}$cells obviously decreased in multiple sclerosis (MS) cases, while the remission of fingolimod-induced relapsed-remitted MS is related to a significantly increased number of $\mathrm{CD} 19^{+} / \mathrm{BTLA}^{+} / \mathrm{IL}-10^{+}$B lymphocytes (80). In patients with active systemic lupus erythematosus (SLE), the proportion of $\mathrm{CD}^{+}{ }^{+} \mathrm{BTLA}^{+} \mathrm{T}$ cells is markedly decreased (81). Sawaf et al. found that in SLE cases, BTLA had a lower ability to suppress the activation of $\mathrm{T}$ cells, and such impaired BTLA function in lupus $\mathrm{CD} 4^{+} \mathrm{T}$ cells was found to be related to disease activity (82). BTLA deficiency accelerates the lupus-like phenotype in autoimmune-prone MRL-lpr/lpr mice, and severe lymphocytic infiltration is detected in the lungs, kidneys, salivary glands, joints, and pancreas (83). However, a study conducted in the Japanese population showed that there was no significant difference in haplotypes, genotypes, and alleles of the BTLA gene between SLE and healthy groups (84). AntiBTLA mAb treatment can delay the onset of autoimmune diabetes in non-obese diabetic (NOD) mice, increase the proportion of Tregs, and direct the cytokine milieu away from autoimmunity (85). Transferring transgenic BTLA-expressing DCs into NOD mice markedly triggers the tolerance of $\mathrm{CD} 8^{+} \mathrm{T}$ cells, while attenuating the autoimmune diabetes severity (86). In rheumatoid arthritis (RA) patients, BTLA-expressing $\mathrm{CD}^{+} /$ $\mathrm{CD}^{+} / \mathrm{CD}^{+} \mathrm{T}$ cell proportions are remarkably increased, and the swollen joint count is negatively correlated with the percentage of $\mathrm{BTLA}^{+} \mathrm{CD}^{+} \mathrm{T}$ cells (87). Lin et al. found that the C+800T SNP in the BTLA gene was associated with RA susceptibility (88). Besides, the 590C SNP, a functional polymorphism of the BTLA gene, is markedly associated with RA susceptibility in the Japanese population (89).

\section{BTLA and Infectious Diseases}

Since BTLA can provide both inhibitory and pro-survival signals to $\mathrm{T}$ cells, it plays a dual role during infection. BTLA expression increases in various infectious diseases, which is generally related to an impaired immune response against infection. BTLA is strongly upregulated in both $\mathrm{CD}^{+}$and $\mathrm{CD}^{+} \mathrm{T}$ cells from COVID-19 patients (90). Similarly, BTLA levels increase in $\mathrm{CD}^{+}$and $\mathrm{CD}^{+} \mathrm{T}$ cells from patients with pulmonary tuberculosis, and this is related to disease progression (91). During infection with primary cytomegalovirus (CMV), BTLA is highly induced in $\mathrm{CD} 8^{+} \mathrm{T}$ cells, and BTLA blockade enhances CMV-specific $\mathrm{CD}^{+} \mathrm{T}$ cell proliferation (92). Increased BTLA level in intrahepatic lymphocytes is related to impaired $\mathrm{T}$ cell responses in the process of chronic hepatitis $B$ virus (HBV) infection, whereas blocking BTLA promotes cytokine production and $\mathrm{T}$ cell proliferation (93). In patients with chronic $\mathrm{HBV}$ infection, a subset of antigen-specific $\mathrm{CD} 8^{+} \mathrm{T}$ cells with low IFN$\gamma$ production express high levels of BTLA, and these cells play a vital role in the regulation of $\mathrm{CD}^{+} \mathrm{T}$ cell responses via BTLA signaling (94). In patients with severe community-acquired pneumonia and in mice with acute lung inflammation, circulating $\mathrm{BTLA}^{+} \mathrm{CD} 4^{+}$lymphocyte proportions markedly increased, whereas agonistic anti-BTLA antibody reduced the activation of the NF- $\mathrm{B}$ pathway and attenuated the inflammatory responses (95). In mice infected with the parasitic nematode Strongyloides ratti, BTLA expression in $\mathrm{CD}^{+} \mathrm{T}$ cells was upregulated. Additionally, deficiency of either BTLA or HVEM leads to decreased amounts of adult parasites in the small intestine, while reducing the larval output in the process of infection (96). Moreover, $\mathrm{BTLA}^{-/-}$mice have also shown resistance to infection in several other disease models. During infection with murine hepatitis virus strain-3 $(\mathrm{MHV}-3), \mathrm{BTLA}^{-/-}$mice show markedly improved spleen and liver injuries and reduced mortality (97). BTLA suppresses both the innate and $\mathrm{T} / \mathrm{B}$ cell-dependent adaptive immune responses during experimental malaria, whereas $\mathrm{BTLA}^{-/-}$mice show markedly decreased parasitemia, and early clearance of infections (98). Furthermore, BTLA ${ }^{-/-}$mice are more resistant to listeriosis infection (99), whereas targeting BTLA promotes primary and memory $\mathrm{T}$ cell responses (100) and accelerates early bacterial clearance (99). Interestingly, $\mathrm{BTLA}^{-/-}$mice have a decreased number of Listeria-specific $\mathrm{CD}^{+} \mathrm{T}$ cells, which reveals the dual effects of BTLA in regulating anti-intracellular pathogen responses in the host $(100,101)$. Furthermore, HVEM expression in $\mathrm{CD}^{+} \mathrm{T}$ lymphocytes and BTLA expression in 
other cell types are necessary for the optimal survival of effector and memory T cells, suggesting that the BTLA/HVEM pathway enhances activated $\mathrm{CD}^{+} \mathrm{T}$ cell survival in the process of Listeria infection (101). During vaccinia virus infection, BTLA or HVEM deficiency markedly damages the survival of effector $\mathrm{CD}^{+} \mathrm{T}$ cells and protective immune memory (102). BTLA ${ }^{+} \alpha \beta$ T cells display a central memory phenotype to combat Mycobacterium tuberculosis ( $\mathrm{Mtb}$ ) infection, as manifested by increased cell proliferation and cytokine secretion, suggesting that BTLA expression in $\alpha \beta T$ cells is involved in protective immune memory against Mtb infection among patients with active pulmonary tuberculosis (103).

\section{BTLA and Transplantation Rejection}

The inhibitory role of BTLA on T cells has also been supported by transplantation studies. BTLA can inhibit donor anti-host $\mathrm{T}$ cell responses and ameliorate graft-versus-host disease (GVHD) resulting from allogeneic bone marrow transplantation (104, 105). In patients with acute renal allograft rejection, BTLA levels in peripheral $\mathrm{CD}^{+} \mathrm{T}$ lymphocytes are markedly lower than those in normal controls who show stable functions of the transplanted kidney $(106,107)$. Agonistic anti-BTLA antibody treatment prolongs cardiac allograft survival in mice with increased $\mathrm{CD} 4^{+} \mathrm{CD} 25^{+}$Foxp $^{+}$cells and reduced IL- 2 and IFN- $\gamma$ production (108). Furthermore, BTLA overexpression in a rat model can markedly suppress acute kidney rejection and extend allograft survival (106). Partially MHC-mismatched allografts can potently induce BTLA expression, while targeting BTLA prompts rapid rejection (109). Agonistic antiBTLA antibody combined with CTLA-4 immunoglobulin treatment can prolong the survival of islet allografts, while promoting indefinite graft acceptance $(110,111)$. Moreover, according to the latest research, overexpression of BTLA combined with CTLA-4 in kidney transplant recipients reduced IL-2 production, suppressed $\mathrm{T}$ cell proliferation, improved graft function, attenuated acute $\mathrm{T}$ cell-mediated rejection, and extended graft survival (112). However, there have been some contradictory reports. For example, Del Rio et al. reported that BTLA blockade alleviated acute GVHD reaction in an F1 transfer semiallogeneic murine model $(113,114)$. Rodriguez-Barbosa et al. found that targeting BTLA/HVEM showed no effect on modulating graft rejection across a fully MHC mismatched barrier and that the donorspecific allogeneic immune response was independent of the HVEM/BTLA signaling pathway (115). Besides, Wang et al. explored the role of BTLA and HVEM polymorphisms in antibody-mediated rejection in renal transplant recipients and found that none of the polymorphisms identified was associated with antibody-mediated rejection (116).

\section{PERSPECTIVES}

BTLA has been found to affect the function of a variety of immune cells and plays an important role in many immunerelated diseases (Table 1). There is growing evidence that BTLA can provide both inhibitory and pro-survival signals to $\mathrm{T}$ cells. As a result, BTLA is found to play dual roles in tumor $(7,55,56)$
TABLE 1 | Reported functions of BTLA in immune-related diseases.

\begin{tabular}{|c|c|}
\hline Disease & Reported functions (references) \\
\hline Tumors & $\begin{array}{l}\text { BTLA expression increases in patients with GBC (44), HCC } \\
(45,46) \text {, DLBCL }(47) \text {, and melanoma }(48,49) \text {, and is } \\
\text { associated with poor prognosis. }\end{array}$ \\
\hline $\begin{array}{l}\text { Inflammatory } \\
\text { diseases }\end{array}$ & $\begin{array}{l}\text { Alleviates allergic airway inflammation (62), contact } \\
\text { hypersensitivity (63), colitis (64), and acute hepatitis (65) in } \\
\text { mice. }\end{array}$ \\
\hline Sepsis & $\begin{array}{l}\text { Increased BTLA correlates with sepsis severity in patients } \\
(68-71) \text {. } \\
\text { BTLA }{ }^{-/-} \text {mice show reduced mortality }(67) \text {. }\end{array}$ \\
\hline $\begin{array}{l}\text { Autoimmune } \\
\text { diseases }\end{array}$ & $\begin{array}{l}\text { The expression of BTLA is decreased in MS (80) and SLE } \\
\text { (81) patients, and increased in RA }(87) \text { patients. } \\
\text { Decreases susceptibility to EAE }(4,78) \text {, autoimmune } \\
\text { hepatitis }(79) \text {, and autoimmune diabetes }(85,86) \text { in mice. }\end{array}$ \\
\hline $\begin{array}{l}\text { Infectious } \\
\text { diseases }\end{array}$ & $\begin{array}{l}\text { BTLA expression increases in patients with COVID-19 (90), } \\
\text { Mtb (91), CMV (92), and HBV (93) infection. } \\
\text { - } \text { BTLA }^{-/-} \text {mice are more resistant to helminth (96), MHV-3 } \\
\text { (97), Plasmodium yoelii strain 17NL (98), and listeriosis infection } \\
\text { (99). }\end{array}$ \\
\hline $\begin{array}{l}\text { Transplantation } \\
\text { rejection }\end{array}$ & $\begin{array}{l}\text { Improves GVHD }(104,105) \text { and prolongs allograft survival } \\
\text { in animal models }(106,108-112) \text {. }\end{array}$ \\
\hline
\end{tabular}

and infection $(101,102)$ immunity, and the function of BTLA in related diseases may be context specific. BTLA can be expressed by numerous cell types. At present, the existing studies on BTLA mainly focus on $\mathrm{T}$ and $\mathrm{B}$ cells, and thus studies on the function of BTLA in other immune cells should be strengthened. Numerous clones of anti-BTLA antibodies have been developed, and the main antibody clones such as 6A6 and 6F7 were summarized in the review by Crawford and Wherry (75). Studies have examined the role of anti-BTLA antibodies in tumor, inflammatory diseases, and transplantation rejection. The findings show that BTLA-neutralizing antibodies can inhibit tumor development (50), while agonistic anti-BTLA antibody treatment reduces inflammation $(63,95)$ and prolongs allograft survival $(108,110,111)$. However, these antibodies may not always act exactly as predicted, since different BTLA antibodies may have opposite functions. Confusingly, even the same clone antibody has been reported to exert opposite effects $(75,85,117)$. Furthermore, considering that BTLA/HVEM can deliver bidirectional signals, antibodies targeting BTLA will cause complex biological effects. Although few therapeutic agents targeting inhibitory receptors (such as CTLA-4Ig and anti-PD-1) are being used in clinical trials, the complexity of BTLA signaling system remains a challenge for the development of targeted therapies.

In addition to BTLA, HVEM interacts with LIGHT and CD160. All the four molecules form the HVEM/BTLA/CD160/ LIGHT signaling network. For HVEM, binding to BTLA mediates the inhibitory effect, while binding to LIGHT mediates the activation effect. The role of CD160 remains controversial as it generates activating as well as inhibitory signals. In response to HVEM ligation, CD160 delivers coinhibitory signals to CD4 ${ }^{+} \mathrm{T}$ cells (8), whereas it provides costimulatory signals to $\mathrm{CD}^{+} \mathrm{T}$ (118) and NK (119) cells. Additionally, BTLA can provide negative feedback for NK cell activation by competing with CD160 (119). 


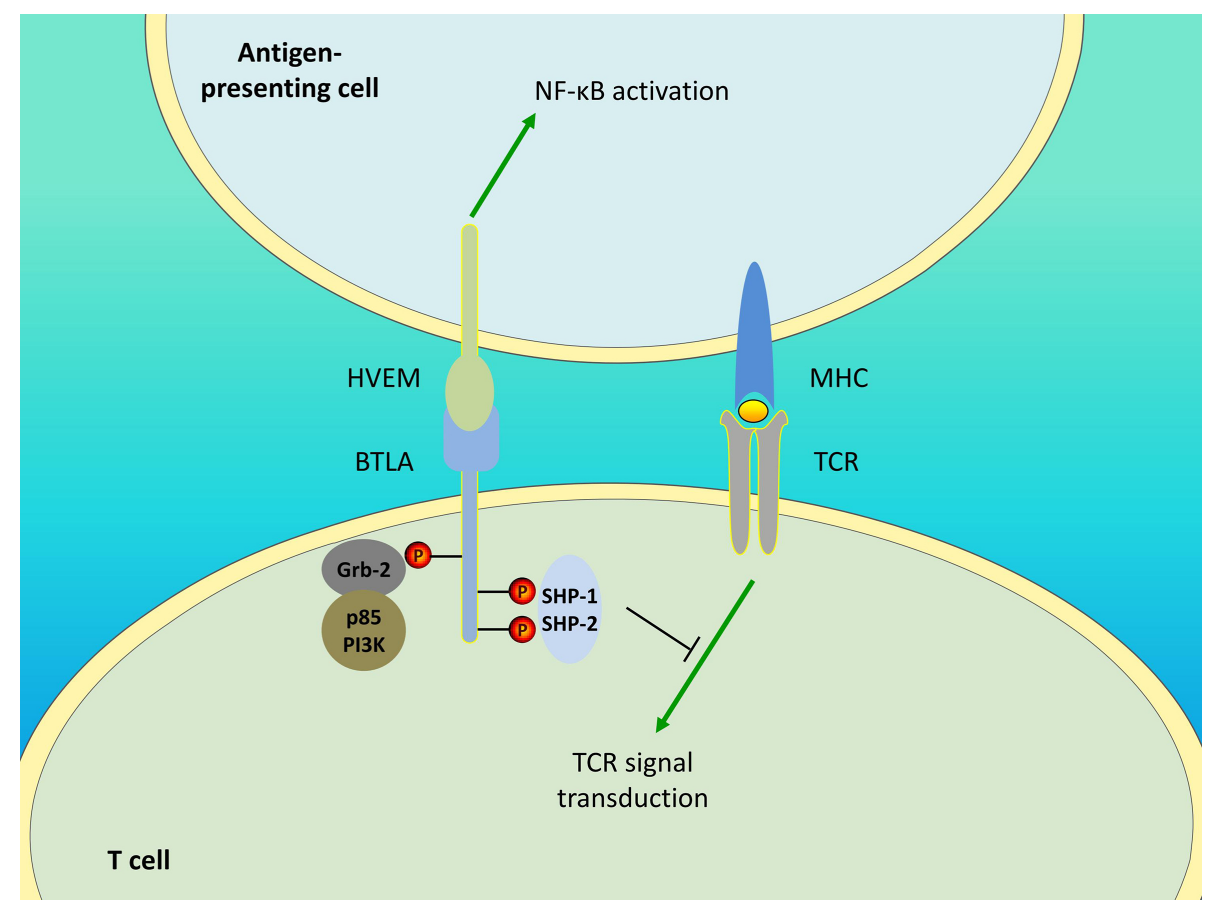

FIGURE 1 | Bidirectional signaling between BTLA and HVEM. Engagement of BTLA leads to SHP-1 and SHP-2 recruitment in T cells, thereby downregulating TCR signaling and delivering inhibitory signals. The Grb-2 association motif binds to Grb-2, leading to the recruitment of PI3K protein subunit p85 and the stimulation of the PI3K signaling pathway. Additionally, BTLA/HVEM signaling is bidirectional. BTLA/HVEM engagement induces HVEM-mediated NF-KB activation in antigenpresenting cells, thus providing proinflammatory and pro-survival signals.

Therefore, HVEM is a bidirectional switch, and its outcome is determined by the ligand involved. In addition, BTLA/HVEM signaling can antagonize LIGHT/HVEM signaling-mediated effector cell activation (14) and additional studies are needed to elucidate which is the predominant pathway. Furthermore, BTLA/ HVEM signaling is also bidirectional. Although BTLA delivers inhibitory signals, its engagement with HVEM induces HVEMmediated NF- $\kappa B$ activation, which is important for the induction of proinflammatory and cell survival genes (120). This also suggests the possibility that the pro-survival effect mediated by BTLA/HVEM ligation may be caused by HVEM-NF- $\mathrm{\kappa B}$ signaling rather than BTLA signaling. The unique interaction between BTLA and HVEM allows for a system of bidirectional signaling (Figure 1), which contributes to the understanding of the opposite or dual roles of HVEM and BTLA and the approach for their specific targeting in treatment.

\section{REFERENCES}

1. Sedy JR, Gavrieli M, Potter KG, Hurchla MA, Lindsley RC, Hildner K, et al. $\mathrm{B}$ and $\mathrm{T}$ lymphocyte attenuator regulates $\mathrm{T}$ cell activation through interaction with herpesvirus entry mediator. Nat Immunol (2005) 6:90-8. doi: 10.1038/ni1144

2. Gonzalez LC, Loyet KM, Calemine-Fenaux J, Chauhan V, Wranik B, Ouyang W, et al. A coreceptor interaction between the CD28 and TNF receptor family members $\mathrm{B}$ and $\mathrm{T}$ lymphocyte attenuator and herpesvirus

\section{AUTHOR CONTRIBUTIONS}

$\mathrm{ZN}$ and $\mathrm{KL}$ are responsible for preparation of the published work. HX is responsible for supervision, review and editing and funding acquisition. All authors contributed to the article and approved the submitted version.

\section{FUNDING}

The present study was funded by the National Natural Science Foundation of China (No. 82003027), Doctoral Startup Fund of Jining Medical University (NO. 2017JYQD24), Research Fund for Academician Lin He New Medicine (NO. JYHL2018MS11), and Chinese and foreign cooperation cultivation project of Jining Medical University.

entry mediator. Proc Natl Acad Sci USA (2005) 102:1116-21. doi: 10.1073/ pnas.0409071102

3. Gavrieli M, Watanabe N, Loftin SK, Murphy TL, Murphy KM. Characterization of phosphotyrosine binding motifs in the cytoplasmic domain of $\mathrm{B}$ and $\mathrm{T}$ lymphocyte attenuator required for association with protein tyrosine phosphatases SHP-1 and SHP-2. Biochem Biophys Res Commun (2003) 312:1236-43. doi: 10.1016/j.bbrc.2003.11.070

4. Watanabe N, Gavrieli M, Sedy JR, Yang J, Fallarino F, Loftin SK, et al. BTLA is a lymphocyte inhibitory receptor with similarities to CTLA-4 and PD-1. Nat Immunol (2003) 4:670-9. doi: 10.1038/ni944 
5. Gavrieli M, Murphy KM. Association of Grb-2 and PI3K p85 with phosphotyrosile peptides derived from BTLA. Biochem Biophys Res Commun (2006) 345:1440-5. doi: 10.1016/j.bbrc.2006.05.036

6. Cheung TC, Oborne LM, Steinberg MW, Macauley MG, Fukuyama S, Sanjo $\mathrm{H}$, et al. T cell intrinsic heterodimeric complexes between HVEM and BTLA determine receptivity to the surrounding microenvironment. J Immunol (2009) 183:7286-96. doi: 10.4049/jimmunol.0902490

7. Murphy TL, Murphy KM. Slow down and survive: Enigmatic immunoregulation by BTLA and HVEM. Annu Rev Immunol (2010) 28:389-411. doi: 10.1146/annurev-immunol-030409-101202

8. Cai G, Anumanthan A, Brown JA, Greenfield EA, Zhu B, Freeman GJ. CD160 inhibits activation of human CD4+ T cells through interaction with herpesvirus entry mediator. Nat Immunol (2008) 9:176-85. doi: 10.1038/ ni1554

9. Zhu Y, Yao S, Augustine MM, Xu H, Wang G, Sun J, et al. Neuron-specific SALM5 limits inflammation in the CNS via its interaction with HVEM. Sci $A d v$ (2016) 2:e1500637. doi: 10.1126/sciadv.1500637

10. Rodriguez-Barbosa JI, Schneider P, Weigert A, Lee KM, Kim TJ, PerezSimon JA, et al. HVEM, a cosignaling molecular switch, and its interactions with BTLA, CD160 and LIGHT. Cell Mol Immunol (2019) 16:679-82. doi: 10.1038/s41423-019-0241-1

11. Yu X, Zheng Y, Mao R, Su Z, Zhang J. BTLA/HVEM Signaling: Milestones in Research and Role in Chronic Hepatitis B Virus Infection. Front Immunol (2019) 10:617. doi: 10.3389/fimmu.2019.00617

12. del Rio ML, Kaye J, Rodriguez-Barbosa JI. Detection of protein on BTLAlow cells and in vivo antibody-mediated down-modulation of BTLA on lymphoid and myeloid cells of C57BL/6 and BALB/c BTLA allelic variants. Immunobiology (2010) 215:570-8. doi: 10.1016/j.imbio.2009.09.008

13. De Sousa Linhares A, Leitner J, Grabmeier-Pfistershammer K, Steinberger P. Not All Immune Checkpoints Are Created Equal. Front Immunol (2018) 9:1909. doi: 10.3389/fimmu.2018.01909

14. Cai G, Freeman GJ. The CD160, BTLA, LIGHT/HVEM pathway: a bidirectional switch regulating T-cell activation. Immunol Rev (2009) 229:244-58. doi: 10.1111/j.1600-065X.2009.00783.x

15. Compaan DM, Gonzalez LC, Tom I, Loyet KM, Eaton D, Hymowitz SG. Attenuating lymphocyte activity: the crystal structure of the BTLA-HVEM complex. J Biol Chem (2005) 280:39553-61. doi: 10.1074/jbc.M507629200

16. Hurchla MA, Sedy JR, Gavrieli M, Drake CG, Murphy TL, Murphy KM. $\mathrm{B}$ and $\mathrm{T}$ lymphocyte attenuator exhibits structural and expression polymorphisms and is highly Induced in anergic CD4+ T cells. J Immunol (2005) 174:3377-85. doi: 10.4049/jimmunol.174.6.3377

17. Krieg C, Han P, Stone R, Goularte OD, Kaye J. Functional analysis of $\mathrm{B}$ and $\mathrm{T}$ lymphocyte attenuator engagement on $\mathrm{CD} 4+$ and $\mathrm{CD} 8+\mathrm{T}$ cells. J Immunol (2005) 175:6420-7. doi: 10.4049/jimmunol.175.10.6420

18. Le Mercier I, Lines JL, Noelle RJ. Beyond CTLA-4 and PD-1, the Generation $\mathrm{Z}$ of Negative Checkpoint Regulators. Front Immunol (2015) 6:418. doi: 10.3389/fimmu.2015.00418

19. Han P, Goularte OD, Rufner K, Wilkinson B, Kaye J. An inhibitory Ig superfamily protein expressed by lymphocytes and APCs is also an early marker of thymocyte positive selection. J Immunol (2004) 172:5931-9. doi: 10.4049/jimmunol.172.10.5931

20. Otsuki N, Kamimura Y, Hashiguchi M, Azuma M. Expression and function of the B and T lymphocyte attenuator (BTLA/CD272) on human T cells. Biochem Biophys Res Commun (2006) 344:1121-7. doi: 10.1016/j.bbrc.2006.03.242

21. Grabmeier-Pfistershammer K, Stecher C, Zettl M, Rosskopf S, Rieger A, Zlabinger GJ, et al. Antibodies targeting BTLA or TIM-3 enhance HIV-1 specific $\mathrm{T}$ cell responses in combination with PD-1 blockade. Clin Immunol (2017) 183:167-73. doi: 10.1016/j.clim.2017.09.002

22. Krieg C, Boyman O, Fu YX, Kaye J. B and T lymphocyte attenuator regulates CD8+ T cell-intrinsic homeostasis and memory cell generation. Nat Immunol (2007) 8:162-71. doi: 10.1038/ni1418

23. Deppong C, Degnan JM, Murphy TL, et al. B and T lymphocyte attenuator regulates T cell survival in the lung. J Immunol (2008) 181:2973-9 doi: 10.4049/jimmunol.181.5.2973

24. Liu X, Alexiou M, Martin-Orozco N, Chung Y, Nurieva RI, Ma L, et al. Cutting edge: A critical role of $\mathrm{B}$ and $\mathrm{T}$ lymphocyte attenuator in peripheral T cell tolerance induction. J Immunol (2009) 182:4516-20 doi: 10.4049/ jimmunol.0803161
25. Chemnitz JM, Lanfranco AR, Braunstein I, Riley JL. B and T lymphocyte attenuator-mediated signal transduction provides a potent inhibitory signal to primary human $\mathrm{CD} 4 \mathrm{~T}$ cells that can be initiated by multiple phosphotyrosine motifs. J Immunol (2006) 176:6603-14 doi: 10.4049/ jimmunol.176.11.6603

26. Xu X, Hou B, Fulzele A, et al. PD-1 and BTLA regulate T cell signaling differentially and only partially through SHP1 and SHP2. J Cell Biol (2020) 219(6):e201905085. doi: 10.1083/jcb.201905085

27. Celis-Gutierrez J, Blattmann P, Zhai Y, Jarmuzynski N, Ruminski K, Grégoire C, et al. Quantitative Interactomics in Primary T Cells Provides a Rationale for Concomitant PD-1 and BTLA Coinhibitor Blockade in Cancer Immunotherapy. Cell Rep (2019) 27:3315-30.e7. doi: 10.1016/ j.celrep.2019.05.041

28. Bekiaris V, Šedý JR, Macauley MG, Rhode-Kurnow A, Ware CF. The inhibitory receptor BTLA controls $\gamma \delta \mathrm{T}$ cell homeostasis and inflammatory responses. Immunity (2013) 39:1082-94. doi: 10.1016/j.immuni.2013.10.017

29. Gertner-Dardenne J, Fauriat C, Orlanducci F, Thibult ML, Pastor S, Fitzgibbon J, et al. The co-receptor BTLA negatively regulates human $\mathrm{V} \gamma 9 \mathrm{~V} \delta 2 \mathrm{~T}$-cell proliferation: a potential way of immune escape for lymphoma cells. Blood (2013) 122:922-31. doi: 10.1182/blood-2012-11464685

30. Vendel AC, Calemine-Fenaux J, Izrael-Tomasevic A, Chauhan V, Arnott D, Eaton DL. B and T lymphocyte attenuator regulates B cell receptor signaling by targeting Syk and BLNK. J Immunol (2009) 182:1509-17. doi: 10.4049/ jimmunol.182.3.1509

31. Kannan S, Kurupati RK, Doyle SA, Freeman GJ, Schmader KE, Ertl HC. BTLA expression declines on B cells of the aged and is associated with low responsiveness to the trivalent influenza vaccine. Oncotarget (2015) 6:1944555. doi: 10.18632/oncotarget.4597

32. Chen YL, Lin HW, Chien CL, Lai YL, Sun WZ, Chen CA, et al. BTLA blockade enhances Cancer therapy by inhibiting IL-6/IL-10-induced CD19 (high) B lymphocytes. J Immunother Cancer (2019) 7:313. doi: 10.1186/ s40425-019-0744-4

33. Thibult ML, Rivals JP, Mamessier E, Gertner-Dardenne J, Pastor S, Speiser DE, et al. CpG-ODN-induced sustained expression of BTLA mediating selective inhibition of human B cells. J Mol Med (Berl) (2013) 91:195-205. doi: 10.1007/s00109-012-0943-7

34. Zhang M, Howard K, Winters A, Steavenson S, Anderson S, Smelt S, et al. Monoclonal antibodies to B and T lymphocyte attenuator (BTLA) have no effect on in vitro $\mathrm{B}$ cell proliferation and act to inhibit in vitro $\mathrm{T}$ cell proliferation when presented in a cis, but not trans, format relative to the activating stimulus. Clin Exp Immunol (2011) 163:77-87. doi: 10.1111/ j.1365-2249.2010.04259.x

35. Mintz MA, Felce JH, Chou MY, Mayya V, Xu Y, Shui JW, et al. The HVEMBTLA Axis Restrains T Cell Help to Germinal Center B Cells and Functions as a Cell-Extrinsic Suppressor in Lymphomagenesis. Immunity (2019) 51:310-23.e7. doi: 10.1016/j.immuni.2019.05.022

36. Kashiwakuma D, Suto A, Hiramatsu Y, Ikeda K, Takatori H, Suzuki K, et al. $\mathrm{B}$ and T lymphocyte attenuator suppresses IL-21 production from follicular Th cells and subsequent humoral immune responses. J Immunol (2010) 185:2730-6. doi: 10.4049/jimmunol.0903839

37. Murphy KM, Nelson CA, Sedy JR. Balancing co-stimulation and inhibition with BTLA and HVEM. Nat Rev Immunol (2006) 6:671-81. doi: 10.1038/ nri1917

38. Kobayashi Y, Iwata A, Suzuki K, Suto A, Kawashima S, Saito Y, et al. B and $\mathrm{T}$ lymphocyte attenuator inhibits LPS-induced endotoxic shock by suppressing Toll-like receptor 4 signaling in innate immune cells. Proc Natl Acad Sci USA (2013) 110:5121-6. doi: 10.1073/pnas.1222093110

39. De Trez C, Schneider K, Potter K, Droin N, Fulton J, Norris PS, et al. The inhibitory HVEM-BTLA pathway counter regulates lymphotoxin receptor signaling to achieve homeostasis of dendritic cells. J Immunol (2008) 180:238-48. doi: 10.4049/jimmunol.180.1.238

40. Xin H, Zhu J, Miao H, Gong Z, Jiang X, Feng X, et al. Adenovirus-Mediated CCR7 and BTLA Overexpression Enhances Immune Tolerance and Migration in Immature Dendritic Cells. Biomed Res Int (2017) 2017:3519745. doi: 10.1155/2017/3519745

41. Jones A, Bourque J, Kuehm L, Opejin A, Teague RM, Gross C, et al. Immunomodulatory Functions of BTLA and HVEM Govern Induction of 
Extrathymic Regulatory T Cells and Tolerance by Dendritic Cells. Immunity (2016) 45:1066-77. doi: 10.1016/j.immuni.2016.10.008

42. Zhang JA, Lu YB, Wang WD, Liu GB, Chen C, Shen L, et al. BTLAExpressing Dendritic Cells in Patients With Tuberculosis Exhibit Reduced Production of IL-12/IFN- $\alpha$ and Increased Production of IL- 4 and TGF- $\beta$, Favoring Th2 and Foxp3(+) Treg Polarization. Front Immunol (2020) 11:518. doi: 10.3389/fimmu.2020.00518

43. Chevalier MF, Bohner P, Pieraerts C, Lhermitte B, Gourmaud J, Nobile A, et al. Immunoregulation of Dendritic Cell Subsets by Inhibitory Receptors in Urothelial Cancer. Eur Urol (2017) 71:854-7. doi: 10.1016/j.eururo. 2016.10.009

44. Oguro S, Ino Y, Shimada K, Hatanaka Y, Matsuno Y, Esaki M, et al. Clinical significance of tumor-infiltrating immune cells focusing on BTLA and Cbl-b in patients with gallbladder cancer. Cancer Sci (2015) 106:1750-60. doi: $10.1111 /$ cas. 12825

45. Liu J, Li J, He M, Zhang GL, Zhao Q. Distinct Changes of BTLA and HVEM Expressions in Circulating CD4(+) and CD8(+) T Cells in Hepatocellular Carcinoma Patients. J Immunol Res (2018) 2018:4561571. doi: 10.1155/2018/ 4561571

46. Zhao Q, Huang ZL, He M, Gao Z, Kuang DM. BTLA identifies dysfunctional PD-1-expressing CD4(+) T cells in human hepatocellular carcinoma. Oncoimmunology (2016) 5:e1254855. doi: 10.1080/2162402X. 2016.1254855

47. Quan L, Lan X, Meng Y, Guo X, Guo Y, Zhao L, et al. BTLA marks a less cytotoxic T-cell subset in diffuse large B-cell lymphoma with high expression of checkpoints. Exp Hematol (2018) 60:47-56.e1. doi: 10.1016/ j.exphem.2018.01.003

48. Derré L, Rivals JP, Jandus C, Pastor S, Rimoldi D, Romero P, et al. BTLA mediates inhibition of human tumor-specific CD8+ T cells that can be partially reversed by vaccination. J Clin Invest (2010) 120:157-67. doi: $10.1172 /$ JCI40070

49. Fourcade J, Sun Z, Pagliano O, Guillaume P, Luescher IF, Sander C, et al. CD8(+) T cells specific for tumor antigens can be rendered dysfunctional by the tumor microenvironment through upregulation of the inhibitory receptors BTLA and PD-1. Cancer Res (2012) 72:887-96. doi: 10.1158/ 0008-5472.CAN-11-2637

50. Sekar D, Govene L, Del Rio ML, Sirait-Fischer E, Fink AF, Brune B, et al. Downregulation of BTLA on NKT Cells Promotes Tumor Immune Control in a Mouse Model of Mammary Carcinoma. Int J Mol Sci (2018) 19 (3):E752. doi: 10.3390/ijms19030752

51. Wang XF, Chen YJ, Wang Q, Ge Y, Dai Q, Yang KF, et al. Distinct expression and inhibitory function of $\mathrm{B}$ and $\mathrm{T}$ lymphocyte attenuator on human T cells. Tissue Antigens (2007) 69:145-53. doi: 10.1111/j.13990039.2006.00710.x

52. Wang Q, Zhang J, Tu H, Liang D, Chang DW, Ye Y, et al. Soluble immune checkpoint-related proteins as predictors of tumor recurrence, survival, and $\mathrm{T}$ cell phenotypes in clear cell renal cell carcinoma patients. J Immunother Cancer (2019) 7:334. doi: 10.1186/s40425-019-0810-y

53. Song J, Wu L. Friend or Foe: Prognostic and Immunotherapy Roles of BTLA in Colorectal Cancer. Front Mol Biosci (2020) 7:148. doi: 10.3389/ fmolb.2020.00148

54. Radvanyi LG, Bernatchez C, Zhang M, Fox PS, Miller P, Chacon J, et al. Specific lymphocyte subsets predict response to adoptive cell therapy using expanded autologous tumor-infiltrating lymphocytes in metastatic melanoma patients. Clin Cancer Res (2012) 18:6758-70. doi: 10.1158/ 1078-0432.ccr-12-1177

55. Haymaker CL, Wu RC, Ritthipichai K, Bernatchez C, Forget MA, Chen JQ, et al. BTLA marks a less-differentiated tumor-infiltrating lymphocyte subset in melanoma with enhanced survival properties. Oncoimmunology (2015) 4: e1014246. doi: 10.1080/2162402X.2015.1014246

56. Ritthipichai K, Haymaker CL, Aschenbrenner A, Yi X, Zhang M, et al. Multifaceted Role of BTLA in the Control of CD8(+) T-cell Fate after Antigen Encounter. Clin Cancer Res (2017) 23:6151-64. doi: 10.1158/10780432.CCR-16-1217

57. Partyka A, Tupikowski K, Kolodziej A, Zdrojowy R, Halon A, Malkiewicz B, et al. Association of 3' nearby gene BTLA polymorphisms with the risk of renal cell carcinoma in the Polish population. Urol Oncol (2016) 34:419.e139. doi: 10.1016/j.urolonc.2016.04.010
58. Karabon L, Partyka A, Jasek M, Lech-Maranda E, Grzybowska-Izydorczyk O, Bojarska-Junak A, et al. Intragenic Variations in BTLA Gene Influence mRNA Expression of BTLA Gene in Chronic Lymphocytic Leukemia Patients and Confer Susceptibility to Chronic Lymphocytic Leukemia. Arch Immunol Ther Exp (Warsz) (2016) 64:137-45. doi: 10.1007/s00005016-0430-x

59. Tang W, Chen S, Kang M, Liu J, Liu C, et al. Investigation of BTLA tagging variants with risk of esophagogastric junction adenocarcinoma. Biosci Rep (2019) 39(12) :BSR20191770. doi: 10.1042/BSR20191770

60. Fu Z, Li D, Jiang W, Wang L, Zhang J, Xu F, et al. Association of BTLA gene polymorphisms with the risk of malignant breast cancer in Chinese women of Heilongjiang Province. Breast Cancer Res Treat (2010) 120:195-202. doi: 10.1007/s10549-009-0462-6

61. Cao R, Tang W, Chen S. Association between BTLA polymorphisms and susceptibility to esophageal squamous cell carcinoma in the Chinese population. J Clin Lab Anal (2020) 34:e23221. doi: 10.1002/jcla.23221

62. Deppong C, Juehne TI, Hurchla M, Friend LD, Shah DD, Rose CM, et al. Cutting edge: $\mathrm{B}$ and $\mathrm{T}$ lymphocyte attenuator and programmed death receptor-1 inhibitory receptors are required for termination of acute allergic airway inflammation. J Immunol (2006) 176:3909-13. doi: 10.4049/jimmunol.176.7.3909

63. Nakagomi D, Suzuki K, Hosokawa J, Kobayashi Y, Suto A, Takatori H, et al. Therapeutic potential of $\mathrm{B}$ and $\mathrm{T}$ lymphocyte attenuator expressed on CD8+ T cells for contact hypersensitivity. J Invest Dermatol (2013) 133:702-11. doi: 10.1038/jid.2012.396

64. Zhang HX, Zhu B, Fu XX, Zeng JC, Zhang JA, Wang WD, et al. BTLA associates with increased Foxp3 expression in CD4(+) T cells in dextran sulfate sodium-induced colitis. Int J Clin Exp Pathol (2015) 8:1259-69.

65. Miller ML, Sun Y, Fu YX. Cutting edge: B and T lymphocyte attenuator signaling on NKT cells inhibits cytokine release and tissue injury in early immune responses. J Immunol (2009) 183:32-6. doi: 10.4049/ jimmunol.0900690

66. Shi W, Shao T, Li JY, Fan DD, Lin AF, Xiang LX, et al. BTLA-HVEM Checkpoint Axis Regulates Hepatic Homeostasis and Inflammation in a ConA-Induced Hepatitis Model in Zebrafish. J Immunol (2019) 203:242542. doi: $10.4049 /$ jimmunol.1900458

67. Shubin NJ, Chung CS, Heffernan DS, Irwin LR, Monaghan SF, Ayala A, et al. BTLA expression contributes to septic morbidity and mortality by inducing innate inflammatory cell dysfunction. J Leukoc Biol (2012) 92:593-603. doi: $10.1189 / \mathrm{jlb} .1211641$

68. Shubin NJ, Monaghan SF, Heffernan DS, Chung CS, Ayala A, et al. B and T lymphocyte attenuator expression on CD4+ T-cells associates with sepsis and subsequent infections in ICU patients. Crit Care (2013) 17:R276. doi: $10.1186 / \mathrm{cc} 13131$

69. Liu Q, Lu Y, An L, Li CS. B- and T-Lymphocyte Attenuator Expression on Regulatory T-Cells in Patients with Severe Sepsis. Chin Med J (Engl) (2018) 131:2637-9. doi: 10.4103/0366-6999.244104

70. Monaghan SF, Banerjee D, Chung CS, Lomas-Neira J, Cygan KJ, Rhine CL, et al. Changes in the process of alternative RNA splicing results in soluble B and $\mathrm{T}$ lymphocyte attenuator with biological and clinical implications in critical illness. Mol Med (2018) 24:32. doi: 10.1186/s10020-018-0036-3

71. Lange A, Sundén-Cullberg J, Magnuson A, Hultgren O. Soluble B and T Lymphocyte Attenuator Correlates to Disease Severity in Sepsis and High Levels Are Associated with an Increased Risk of Mortality. PloS One (2017) 12:e0169176. doi: 10.1371/journal.pone.0169176

72. Shao R, Li CS, Fang Y, Zhao L, Hang C, et al. Low B and T lymphocyte attenuator expression on $\mathrm{CD} 4+\mathrm{T}$ cells in the early stage of sepsis is associated with the severity and mortality of septic patients: a prospective cohort study. Crit Care (2015) 19:308. doi: 10.1186/s13054-015-1024-4

73. Spec A, Shindo Y, Burnham CA, Wilson S, Ablordeppey EA, Beiter ER, et al. $\mathrm{T}$ cells from patients with Candida sepsis display a suppressive immunophenotype. Crit Care (2016) 20:15. doi: 10.1186/s13054-016-1182-z

74. Lepenies B, Pfeffer K, Hurchla MA, Murphy TL, Murphy KM, Oetzel J, et al. Ligation of $\mathrm{B}$ and $\mathrm{T}$ lymphocyte attenuator prevents the genesis of experimental cerebral malaria. J Immunol (2007) 179:4093-100. doi: 10.4049/jimmunol.179.6.4093

75. Crawford A, Wherry EJ. Editorial: Therapeutic potential of targeting BTLA. J Leukoc Biol (2009) 86:5-8. doi: 10.1189/jlb.0209076 
76. Cheng T, Bai J, Chung CS, Chen Y, Biron BM, Ayala A, et al. Enhanced Innate Inflammation Induced by Anti-BTLA Antibody in Dual Insult Model of Hemorrhagic Shock/Sepsis. Shock (2016) 45:40-9. doi: 10.1097/ SHK.0000000000000479

77. Gan L, Hu C, Deng Z, Lu H, Sun J, Peng G, et al. Rs1982809 is a functional biomarker for the prognosis of severe post-traumatic sepsis and MODs. Exp Biol Med (Maywood) (2019) 244:1438-45. doi: 10.1177/1535370219880490

78. Huarte E, Jun S, Rynda-Apple A, Rynda-Apple A, Rynda-Apple A, RyndaApple A, et al. Regulatory $\mathrm{T}$ Cell Dysfunction Acquiesces to BTLA+ Regulatory B Cells Subsequent to Oral Intervention in Experimental Autoimmune Encephalomyelitis. J Immunol (2016) 196:5036-46. doi: 10.4049/jimmunol.1501973

79. Oya Y, Watanabe N, Owada T, Oki M, Hirose K, Suto A, et al. Development of autoimmune hepatitis-like disease and production of autoantibodies to nuclear antigens in mice lacking B and T lymphocyte attenuator. Arthritis Rheum (2008) 58:2498-510. doi: 10.1002/art.23674

80. Piancone F, Saresella M, Marventano I, La Rosa F, Zoppis M, Agostini S, et al. B Lymphocytes in Multiple Sclerosis: Bregs and BTLA/CD272 Expressing-CD19+ Lymphocytes Modulate Disease Severity. Sci Rep (2016) 6:29699. doi: 10.1038/srep29699

81. Oster C, Wilde B, Specker C, Sun M, Kribben A, Witzke O, et al. BTLA Expression on Th1, Th2 and Th17 Effector T-Cells of Patients with Systemic Lupus Erythematosus Is Associated with Active Disease. Int J Mol Sci (2019) 20 (18):E4505 .doi: 10.3390/ijms20184505

82. Sawaf M, Fauny JD, Felten R, Sagez F, Gottenberg JE, Dumortier H, et al. Defective BTLA functionality is rescued by restoring lipid metabolism in lupus CD4+ T cells. JCI Insight (2018) 3 (13) :e99711. doi: 10.1172/jci. insight.99711

83. Oya Y, Watanabe N, Kobayashi Y, Owada T, Oki M, Ikeda K, et al. Lack of B and $\mathrm{T}$ lymphocyte attenuator exacerbates autoimmune disorders and induces Fas-independent liver injury in MRL-lpr/lpr mice. Int Immunol (2011) 23:335-44. doi: 10.1093/intimm/dxr017

84. Inuo $\mathrm{M}$, Ihara $\mathrm{K}$, Matsuo $\mathrm{T}$, Kohno $\mathrm{H}$, Hara $\mathrm{T}$, et al. Association study between B- and T-lymphocyte attenuator gene and type 1 diabetes mellitus or systemic lupus erythematosus in the Japanese population. Int $J$ Immunogenet (2009) 36:65-8. doi: 10.1111/j.1744-313X.2008.00809.x

85. Truong W, Hancock WW, Plester JC, Merani S, Rayner DC, Thangavelu G, et al. BTLA targeting modulates lymphocyte phenotype, function, and numbers and attenuates disease in nonobese diabetic mice. J Leukoc Biol (2009) 86:41-51. doi: 10.1189/jlb.1107753

86. Li S, Zhang M, Xiang F, Zhao J, Jiang C, Zhu J, et al. Dendritic cells expressing BTLA induces CD8 $+\mathrm{T}$ cell tolerance and attenuates the severity of diabetes. Vaccine (2011) 29:7747-51. doi: 10.1016/j.vaccine. 2011.07.125

87. Yang B, Huang Z, Feng W, Wei W, Zhang J, Liao Y, et al. The Expression of BTLA Was Increased and the Expression of HVEM and LIGHT Were Decreased in the T Cells of Patients with Rheumatoid Arthritis [corrected]. PloS One (2016) 11:e0155345. doi: 10.1371/journal.pone.0155345

88. Lin SC, Kuo CC, Chan CH. Association of a BTLA gene polymorphism with the risk of rheumatoid arthritis. J BioMed Sci (2006) 13:853-60. doi: 10.1007/ s11373-006-9113-7

89. Oki M, Watanabe N, Owada T, Oya Y, Ikeda K, Saito Y, et al. A functional polymorphism in $\mathrm{B}$ and $\mathrm{T}$ lymphocyte attenuator is associated with susceptibility to rheumatoid arthritis. Clin Dev Immunol (2011) 2011:305656. doi: 10.1155/2011/305656

90. Schultheiß C, Paschold L, Simnica D, Mohme M, Willscher E, von Wenserski L, et al. Next-Generation Sequencing of T and B Cell Receptor Repertoires from COVID-19 Patients Showed Signatures Associated with Severity of Disease. Immunity (2020) 53:442-55.e4. doi: 10.1016/ j.immuni.2020.06.024

91. Shen X, Zhang J, Tang P, Song H, Liu X, Huang Z, et al. Expression and clinical significance of $\mathrm{B}$ and $\mathrm{T}$ lymphocyte attenuator on CD4(+) and CD8 (+) $\mathrm{T}$ cells from patients with pulmonary tuberculosis. Indian J Pathol Microbiol (2019) 62:232-8. doi: 10.4103/IJPM.IJPM_727_17

92. Serriari NE, Gondois-Rey F, Guillaume Y, Remmerswaal EB, Pastor S, Messal $\mathrm{N}$, et al. B and $\mathrm{T}$ lymphocyte attenuator is highly expressed on $\mathrm{CMV}$-specific $\mathrm{T}$ cells during infection and regulates their function. J Immunol (2010) 185:3140-8. doi: 10.4049/jimmunol.0902487
93. Cai G, Nie X, Li L, Hu L, Wu B, Lin J, et al. B and T lymphocyte attenuator is highly expressed on intrahepatic T cells during chronic HBV infection and regulates their function. J Gastroenterol (2013) 48:1362-72. doi: 10.1007/ s00535-013-0762-9

94. Wang H, Wu B, Li L, Hu L, Lin J, Jiang C, et al. Hepatic expansion of virusspecific CD8(+)BTLA(+) $\mathrm{T}$ cells with regulatory properties in chronic hepatitis B virus infection. Cell Immunol (2017) 311:36-45. doi: 10.1016/ j.cellimm.2016.10.002

95. Zhou G, Wang D, Liu D, Qi D, Liu Z, et al. Expression of B and T Lymphocyte Attenuator in Patients with Severe Community-Acquired Pneumonia and the Effect of Steroid Therapy in a Mouse Model. Clin Lab (2016) 62:2367-77. doi: 10.7754/Clin.Lab.2016.160521

96. Breloer M, Hartmann W, Blankenhaus B, Eschbach ML, Pfeffer K, Jacobs T, et al. Cutting Edge: the BTLA-HVEM regulatory pathway interferes with protective immunity to intestinal Helminth infection. J Immunol (2015) 194:1413-6. doi: 10.4049/jimmunol.1402510

97. Yang C, Chen Y, Guo G, Li H, Cao D, Xu H, et al. Expression of B and T lymphocyte attenuator (BTLA) in macrophages contributes to the fulminant hepatitis caused by murine hepatitis virus strain-3. Gut (2013) 62:1204-13. doi: 10.1136/gutjnl-2012-302239

98. Adler G, Steeg C, Pfeffer K, Murphy TL, Murphy KM, Langhorne J, et al. B and $\mathrm{T}$ lymphocyte attenuator restricts the protective immune response against experimental malaria. J Immunol (2011) 187:5310-9. doi: 10.4049/ jimmunol.1101456

99. Sun Y, Brown NK, Ruddy MJ, Miller ML, Lee Y, Wang Y, et al. B and T lymphocyte attenuator tempers early infection immunity. J Immunol (2009) 183:1946-51. doi: 10.4049/jimmunol.0801866

100. Yang X, Zhang X, Sun Y, Tu T, Fu ML, Miller M, et al. A BTLA-mediated bait and switch strategy permits Listeria expansion in $\mathrm{CD} 8 \alpha(+)$ DCs to promote long-term T cell responses. Cell Host Microbe (2014) 16:68-80. doi: 10.1016/j.chom.2014.05.021

101. Steinberg MW, Huang Y, Wang-Zhu Y, Ware CF, Cheroutre H, Kronenberg $M$, et al. BTLA interaction with HVEM expressed on CD8(+) T cells promotes survival and memory generation in response to a bacterial infection. PloS One (2013) 8:e77992. doi: 10.1371/journal.pone.0077992

102. Flynn R, Hutchinson T, Murphy KM, Ware CF, Croft M, Salek-Ardakani S, et al. CD8 $\mathrm{T}$ cell memory to a viral pathogen requires trans cosignaling between HVEM and BTLA. PloS One (2013) 8:e77991. doi: 10.1371/ journal.pone.0077991

103. Zeng JC, Lin DZ, Yi LL, Liu GB, Zhang H, Wang WD, et al. BTLA exhibits immune memory for $\alpha \beta \mathrm{T}$ cells in patients with active pulmonary tuberculosis. Am J Transl Res (2014) 6:494-506.

104. Albring JC, Sandau MM, Rapaport AS, Edelson BT, Satpathy A, Mashayekhi $\mathrm{M}$, et al. Targeting of B and T lymphocyte associated (BTLA) prevents graftversus-host disease without global immunosuppression. J Exp Med (2010) 207:2551-9. doi: 10.1084/jem.20102017

105. Sakoda Y, Park JJ, Zhao Y, Kuramasu A, Geng D, Tao Y, et al. Dichotomous regulation of GVHD through bidirectional functions of the BTLA-HVEM pathway. Blood (2011) 117:2506-14. doi: 10.1182/blood-2010-08-301325

106. Zhang J, Zhang H, Wang Z, Yang H, Chen H, Cheng H, et al. BTLA suppress acute rejection via regulating TCR downstream signals and cytokines production in kidney transplantation and prolonged allografts survival. Sci Rep (2019) 9:12154. doi: 10.1038/s41598-019-48520-7

107. Wang Z, Yang H, Liu X, Zhang J, Han Z, Tao J, et al. Role of B and T Lymphocyte Attenuator in Renal Transplant Recipients with Biopsy-Proven Acute Rejection. Med Sci Monit (2018) 24:387-96. doi: 10.12659/ msm.905752

108. Uchiyama $M$, Jin $X$, Matsuda $H$, Bashuda $H$, Imazuru $T$, Shimokawa $T$, et al. An agonistic anti-BTLA mAb (3C10) induced generation of IL-10dependent regulatory CD4+ $\mathrm{T}$ cells and prolongation of murine cardiac allograft. Transplantation (2014) 97:301-9. doi: 10.1097/01.TP.000043 8204.96723.8b

109. Tao R, Wang L, Han R, Wang T, Ye Q, Honjo T, et al. Differential effects of B and $\mathrm{T}$ lymphocyte attenuator and programmed death-1 on acceptance of partially versus fully MHC-mismatched cardiac allografts. J Immunol (2005) 175:5774-82. doi: 10.4049/jimmunol.175.9.5774

110. Truong W, Plester JC, Hancock WW, Merani S, Murphy TL, Murphy KM, et al. Combined coinhibitory and costimulatory modulation with anti-BTLA 
and CTLA4Ig facilitates tolerance in murine islet allografts. Am J Transplant (2007) 7:2663-74. doi: 10.1111/j.1600-6143.2007.01996.x

111. Truong W, Plester JC, Hancock WW, Kaye J, Merani S, Murphy KM, et al. Negative and positive co-signaling with anti-BTLA (PJ196) and CTLA4Ig prolongs islet allograft survival. Transplantation (2007) 84:1368-72. doi: $10.1097 / 01 . t p .0000289995 .70390 .20$

112. Zhang $H$, Wang Z, Zhang J, Zhang X, Gui Z, Sun L, et al. The synergism of B and T lymphocyte attenuator (BTLA) and cytotoxic T lymphocyte associated antigen-4 (CTLA-4) attenuated acute T-cell mediated rejection and prolonged renal graft survival. Transl Androl Urol (2020) 9:1990-9. doi: $10.21037 /$ tau-20-728

113. del Rio ML, Kurtz J, Perez-Martinez C, Ghosh A, Perez-Simon JA, Rodriguez-Barbosa JI, et al. B- and T-lymphocyte attenuator targeting protects against the acute phase of graft versus host reaction by inhibiting donor anti-host cytotoxicity. Transplantation (2011) 92:1085-93. doi: 10.1097/TP.0b013e3182339d4a

114. del Rio ML, Jones ND, Buhler L, Norris P, Shintani Y, Ware CF, et al. Selective blockade of herpesvirus entry mediator- $\mathrm{B}$ and $\mathrm{T}$ lymphocyte attenuator pathway ameliorates acute graft-versus-host reaction. J Immunol (2012) 188:4885-96. doi: 10.4049/jimmunol.1103698

115. Rodriguez-Barbosa JI, Fernandez-Renedo C, Moral AMB, et al. T follicular helper expansion and humoral-mediated rejection are independent of the HVEM/BTLA pathway. Cell Mol Immunol (2017) 14:497-510. doi: 10.1038/ cmi.2015.101

116. Wang Z, Wang K, Yang H, Han Z, Tao J, Chen H, et al. Associations between HVEM/LIGHT/BTLA/CD160 polymorphisms and the occurrence of antibody-mediate rejection in renal transplant recipients. Oncotarget (2017) 8:100079-94. doi: 10.18632/oncotarget.21941

117. Steinberg MW, Turovskaya O, Shaikh RB, Kim G, McCole DF, Pfeffer K, et al. A crucial role for HVEM and BTLA in preventing intestinal inflammation. J Exp Med (2008) 205:1463-76. doi: 10.1084/jem.20071160

118. Tan CL, Peluso MJ, Drijvers JM. CD160 Stimulates CD8(+) T Cell Responses and Is Required for Optimal Protective Immunity to Listeria monocytogenes. Immunohorizons (2018) 2:238-50. doi: 10.4049/immunohorizons.1800039

119. Šedý JR, Bjordahl RL, Bekiaris V, Macauley MG, Ware BC, Norris PS, et al. CD160 activation by herpesvirus entry mediator augments inflammatory cytokine production and cytolytic function by NK cells. J Immunol (2013) 191:828-36. doi: 10.4049/jimmunol.1300894

120. Shui JW, Steinberg MW, Kronenberg M. Regulation of inflammation, autoimmunity, and infection immunity by HVEM-BTLA signaling. J Leukoc Biol (2011) 89:517-23. doi: 10.1189/jlb.0910528

Conflict of Interest: The authors declare that the research was conducted in the absence of any commercial or financial relationships that could be construed as a potential conflict of interest.

Copyright (๑) 2021 Ning, Liu and Xiong. This is an open-access article distributed under the terms of the Creative Commons Attribution License (CC BY). The use, distribution or reproduction in other forums is permitted, provided the original author(s) and the copyright owner(s) are credited and that the original publication in this journal is cited, in accordance with accepted academic practice. No use, distribution or reproduction is permitted which does not comply with these terms. 